\title{
"ROCAMBOLE-LIKE" BICEPS TENODESIS: TECHNIQUE AND RESULTS
}

Glaydson Gomes Godinho', Fabrício Augusto Silva Mesquita², Flávio de Oliveira França ${ }^{3}$ José Márcio Alves Freitas ${ }^{3}$

\section{ABSTRACT}

Objective: To present a new technique for bicipital tenodesis and its results: accomplished partially via arthroscopy and grounded in concepts of the normal and pathological anatomy of the tendon of the biceps long head. It is based on the predisposition of this tendon towards becoming attached to the intertubercular sulcus after rupture or tenotomy (auto-tenodesis). Methods: Evaluations were conducted on 63 patients (63 shoulders), aged from 32 to 77 years (average $55)$, consisting of 32 females (51\%) and 31 males (49\%). Thirty-five of the patients $(55.6 \%)$ were over 60 years of age and 28 patients $(44.4 \%)$ were under 60 years of age. Eighteen were sports participants (28.6\%). Fourteen had injuries associated with the subscapularis (22.2\%). The average follow up was 43 months (ranging from 12 to 74 months). The right shoulder accounted for 48 cases $(76.2 \%)$, of which one was a left-handed individual and 47 were right-handed. The left shoulder accounted for 15 (23\%) of the patients, of whom two were left-handed and 13 were right-handed. There were no bilateral occurrences. The statistical analysis were

\section{INTRODUCTION}

The origin of the biceps tendon is located in the supraglenoid tubercle in $30 \%$ of cases; in the labrum, in $45 \%$; and mixed in the labrum and tubercle, in $25 \%$. Its course is oblique in the joint, emerges under the transverse humeral ligament inside the intertubercular groove, is intra-articular and extrasynovial. The average length is $102 \mathrm{~mm}$ $(89-146 \mathrm{~mm})$. The proximal area of the glenoid (articular) averages $8.4 \times 3.4 \mathrm{~mm}$. At the exit point of the intertubercular groove (extra-articular) it measures $4.5 \times 2.1 \mathrm{~mm}^{(1)}$. done using SPSS version 18. Pearson's chi-square test and continuity corrections were used to investigate the statistical significance of associations between variables. Associations were taken to be statistically significant when $p$ was less than 0.05. Results: Residual Popeye deformity was perceived by seven patients (11.1\%); it was only observed by the examiner in 15 cases $(23.8 \%)$; and neither the patient nor the examiner observed it in 41 cases (65\%). There were no statistically valid influences from age, participation in contact or throwing sports, subscapularis tendon-associated injury or Popeye deformity. Fifty-eight patients $(92.06 \%)$ were satisfied, two patients were dissatisfied (3.17\%) and three patients were indifferent $(4.76 \%)$. Conclusion: The technique presented high patient satisfaction rates $(92.06 \%)$ and residual deformity was perceived by $11.1 \%$ of the patients. The appearance did not have any statistically valid correlation with ages over or under 60 years $(\mathrm{p}=0.883)$, sports practice $(\mathrm{p}=0.195)$ or subscapularis-associated injury $(\mathrm{p}=0.958)$.

Keywords - Arthroscopy; Shoulder/injuries; Shoulder/surgery

The long head of biceps tendon is a frequent cause of pain in the shoulder.

The pathology of the long head of biceps tendon can be a result of trauma or micro-instability, or a consequence of a chronic inflammatory process due to excessive or degenerative use.

Due to the close relationship with the rotator cuff, mechanical impact against the coracohumeral arch has been reported as the main cause of bicipital degeneration, whose inflammatory response leads to a hypertrophy of the tendon, with pain and dysfunction ${ }^{(2)}$.

\footnotetext{
1 - Head Surgeon of the Shoulder Group of the Lifecenter, Belo Horizonte and Clínica Ortopédico-BH hospitals - Belo Horizonte, MG, Brazil

2 - Third-year Resident of Hospital Belo Horizonte - Belo Horizonte, MG, Brazil.

3 - Surgeon of the Shoulder Group, Hospital Lifecenter and Clínica Ortopédico-BH - Belo Horizonte, MG, Brazil.

Study conducted at the Lifecenter, Belo Horizonte and Clínica Ortopédico-BH hospitals- Belo Horizonte, MG.

Mailing address: Rua Vicente Guimarães, 35/1.002, Belvedere - 30320-640 - Belo Horizonte, MG. Email: ggodinho@terra.com.br

Study received for publication: $2 / 13 / 2011$, accepted for publication: $5 / 25 / 2011$..
}

The authors declare that there was no conflict of interest in conducting this work 
Lesions vary in degree from tendinitis, delamination and subluxation on the medial border of the intertubercular groove, to its full dislocation, which can also cause a glenohumeral articular block ${ }^{(3)}$.

It was demonstrated that the diameter of unhealthy tendons is significantly larger than in normal tendons, and that the force required to cause the distal migration of the biceps is also significantly greater than that necessary in normal tendons ${ }^{(1,2)}$.

Multiple surgical techniques were described for the treatment of bicipital degeneration with the performance of tenodesis ${ }^{(4,5)}$.

Tenodesis was proposed by several authors as an alternative to avoid the cosmetic alteration caused by residual deformity ("Popeye") and possible muscle discomfort after tenotomy ${ }^{(4)}$.

Some techniques use the fixation of the tendon in the intertubercular groove, while others use fixation in soft parts, partially or totally by arthroscopic route. Interference anchors are generally used in these cases ${ }^{(5)}$.

The aim of this study is the presentation of a tenodesis technique developed by the institution's group of shoulder specialists, based on the normal and pathological anatomy of the long biceps tendon. The shape formed by suturing the stump on itself suggests the figure of a "Swiss roll", exacerbating the diameter of the articular extremity of the tendon, which is normally larger than the extra-articular diameter. Consequently, there is an even more pronounced block of its distal migration, performed in a simple, low-cost manner.

\section{METHODS}

A retrospective study was conducted with 81 patients ( 81 shoulders), operated in the period between $4 / 23 / 03$ and $7 / 15 / 09$, on whom we performed biceps tenodesis, according to the technique to be presented.

The study was authorized by the medical ethics committees of the institutions involved.

The criteria of indication of the bicipital tenodesis were: 1) patients submitted to the treatment of degenerative lesions involving approximately $50 \%$ of the diameter of the long head of biceps tendon, associated with rotator cuff lesions or separate; 2) subluxations and dislocations of this tendon ${ }^{(6)}$.

\section{Surgical technique}

Patient positioned in lateral decubitus with vertical and longitudinal traction mechanisms on the arm to be operated. General anesthesia associated with brachial plexus block.

Classic arthroscopic posterior, lateral, anterior superior and anterior inferior portals.

Joint inspection and identification of the bicipital lesion and its extension, besides that of the associated lesions ${ }^{(7)}$.

The biceps tendon is initially transfixed with double-row repair sutures, approximately $1.0 \mathrm{~cm}$ from its origin in the supraglenoid tubercle and upper labrum.

Number 1, monofilament suture thread is used for this purpose, replaced after the passage of number 2 nonabsorbable thread (Figure 1).

The tendon is sectioned close to the upper labrum, taking care to preserve its length as much as possible (Figure 2).

After the tenotomy, the arm is removed from the longitudinal traction mechanism, the elbow is flexed to relax the biceps and the tendon is pulled outside through the anterior superior portal and maintained with maximum exposure while being fixed with a pair of forceps. At this time, the extremity is rolled around itself and transfixed with number 2 nonabsorbable thread, producing a configuration that resembles a "Swiss roll", after which the technique was named (Figures 3A and 3B).

After this, the elbow is once again placed in extension and the arm repositioned in the traction mechanism on the arthroscopy table. When it is distended,

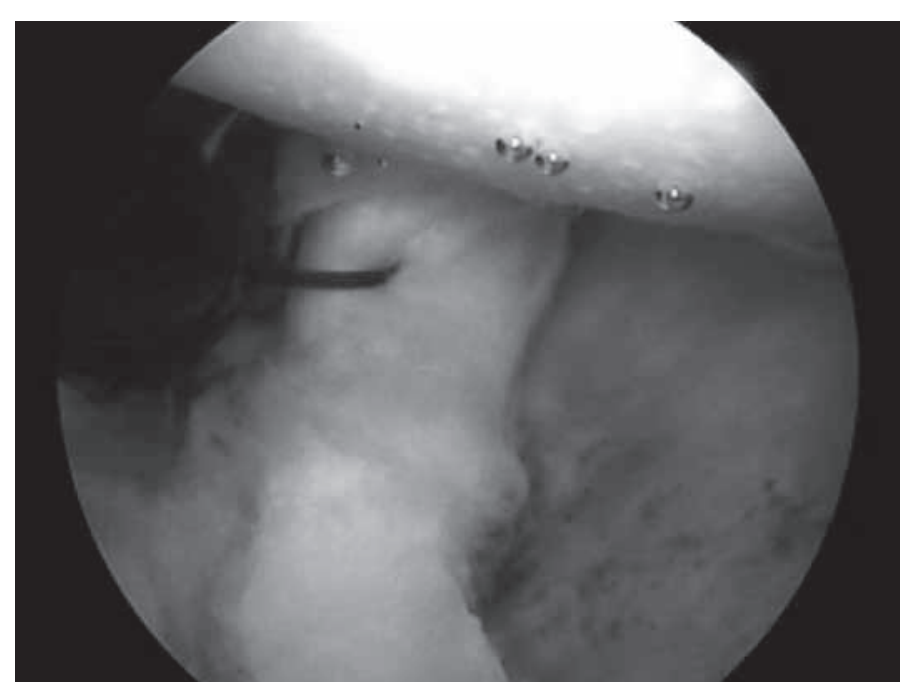

Figure 1 - Transfixation of the biceps tendon with double-row repair suture approximately $1.0 \mathrm{~cm}$ from its origin. 


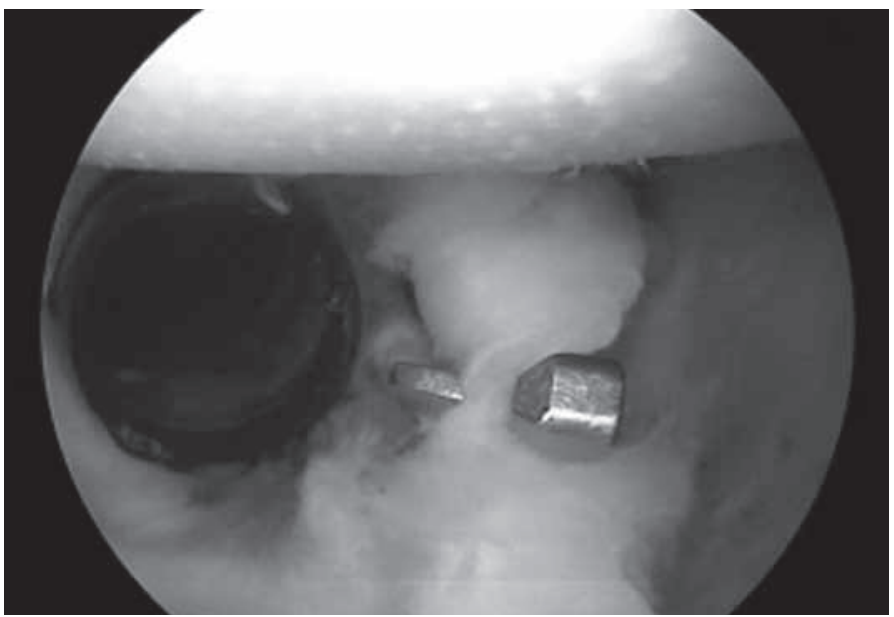

Figure 2 - Biceps tenotomy.

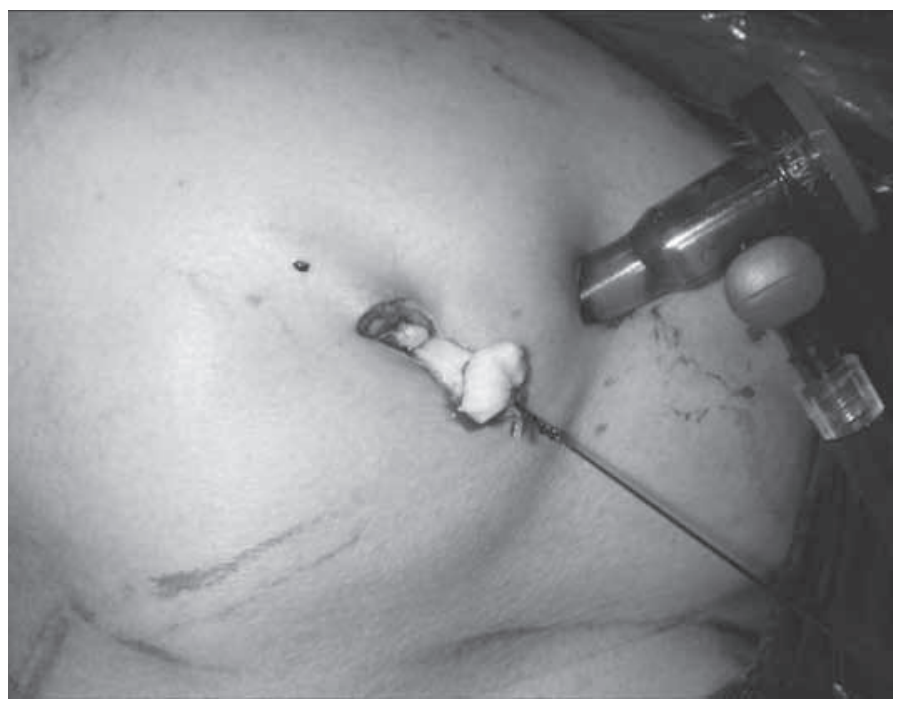

Figure $\mathbf{3 A}$ - Externalization and suturing of the tendon stump on itself.

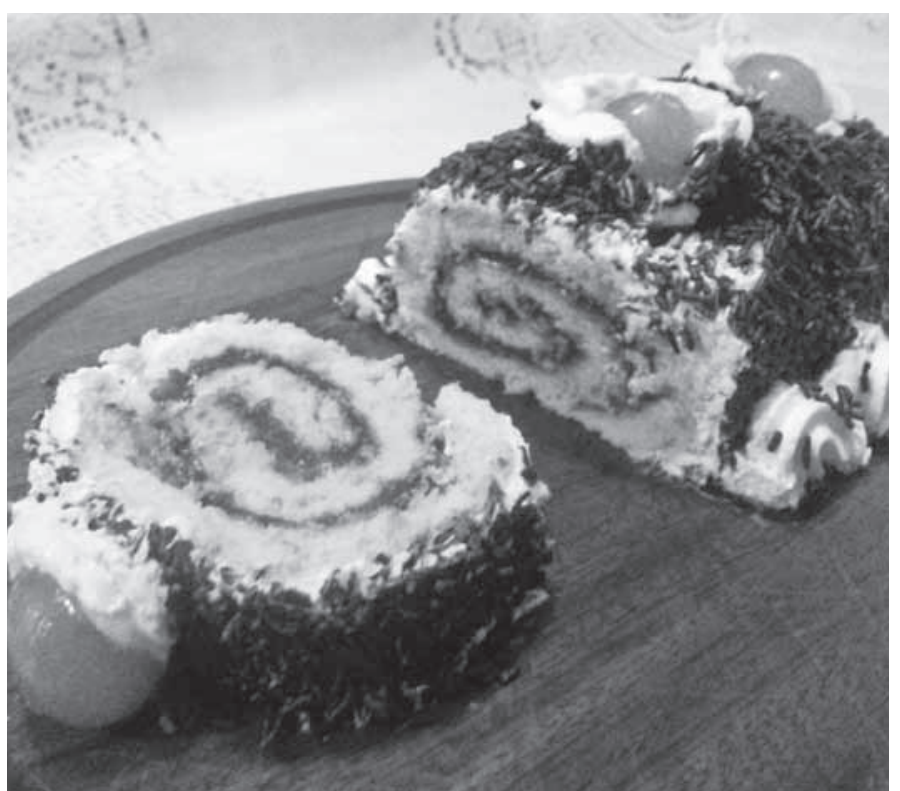

Figure 3B - Swiss roll: the dish whose appearance inspired the name of the technique. the tendon stump migrates to the entrance of the intertubercular groove, where it is blocked. This is followed by the performance of the rotator cuff repair procedure, when necessary.

In the case of deinsertion of the subscapularis tendon, this tendon is reinserted prior to the bicipital tenodesis.

The immobilization time, when dealing with an isolated procedure of the biceps, is three weeks with the use of a velpeau sling. Flexion/extension exercises are allowed once a day, with restriction of the last 30 degrees of extension to avoid forcing the distal migration of the biceps.

When isolated, tenodesis allows patients to resume contact and throwing sports 90 days after surgery. When associated with rotator cuff repair procedures, this resumption will depend on the extension of the cuff lesion, whose protocol is resumption of sports six months after surgery.

The exclusion criteria were: patients with follow-up time of less than 12 months after surgery, those who did not attend the clinical revision and did not present complete medical records.

A total of 63 patients (77.8\%), with 31 (49\%) males and $32(51 \%)$ females, were evaluated. Age ranged from 32 to 77 years, averaging 55 years. Thirty-five patients $(55.0 \%)$ were aged 60 years or over.

The minimum follow-up was 12 months, averaging 43 months, with a maximum of 74 . The right shoulder corresponded to 48 cases $(76.2 \%)$, with one left-handed patient and 47 right-handed patients. The left shoulder represented 15 (23.8\%), with two left-handed patients and 13 right-handed patients. There was no bilateral occurrence.

Eighteen patients $(28.6 \%)$ played sports with direct involvement of the arms.

In 14 patients $(22.2 \%)$ there was concomitant deinsertion of the subscapularis tendon.

All the patients were evaluated by an independent examiner who did not take part in the surgery and the evaluations were carried out in the absence of the surgeons, avoiding the interference of their subjectivity.

The cosmetic perception of the deformity caused by distal migration of the biceps ("Popeye sign") was evaluated based on observations made by the examiner and the patient, as was the latter's degree of satisfaction. Alteration of strength of elbow flexion and forearm supination, presence of pain or muscle 
fatigue and influence of the associated subscapularis tendon lesion and of playing sports involving direct action of the arms on the results were also evaluated.

The patients were asked the following question: "Do you notice any modification in the contour of your operated arm in comparison to the non-operated arm? Are you satisfied, dissatisfied or indifferent in relation to your arm's appearance?"

The examiner was expected to verify the presence or absence of residual deformity in the arm, as well as pain and/or muscle fatigue, and to perform the clinical evaluation of elbow and forearm flexion strength.

\section{STATISTICAL ANALYSIS}

The statistical analysis was carried out according to the resources of version 18 of the SPSS statistical program. Descriptive measures (mean and standard deviation, minimum and maximum) were used for the quantitative variables with frequency distributions for the qualitative variables ${ }^{(8,9)}$.

Contingency tables were used to associate the observer's objective evaluation with the following variables: age bracket, physical activity, presence of lesions of the subscapularis tendon in the operated patients and objective evaluation of the patients. Pearson's chi-square test, with continuity correction, was adopted to test the statistical significance of the association between and among such variables.

A significance level of 5\% was considered in all the statistical tests used. Therefore associations whose $\mathrm{p}$ value was below 0.05 are considered statistically significant ${ }^{(8,9)}$.

\section{RESULTS}

The results indicated that there is correlation between the evaluation of Popeye deformity carried out by the observer (examiner) and the patient. However, the observer's evaluation to identify the presence of Popeye is more concise than that of the patient $(\mathrm{p}=0.001)($ Table 1$)$.

We were able to observe that the variable age of patients did not have statistical significance in the cross-evaluation with the occurrence of Popeye deformity $(\mathrm{p}=0.883)$ (Table 2 and Figure 4).

The statistical analysis showed absence of valid correlation between the practice of sports and the occurrence of Popeye deformity $(p=0.195)$ (Table 3 and Figure 5).
No statistically valid correlation was observed between the subscapularis tendon lesion and its corresponding repair with the occurrence of residual Popeye deformity $(\mathrm{p}=0.958)$ (Table 4$)$.

Fifty-eight patients (92\%) declared themselves satisfied; two (3.2\%) dissatisfied; and three (4.8\%) indifferent.

No difference of strength of elbow flexion or forearm supination was observed during the physical evaluation in any patient.

Weak residual pain was reported by two patients, which correspond to the unsatisfactory results $(3.2 \%)$ (Figure 6).

Table 1 - Analysis of the correlation between the objective evaluation of the patient and of the examiner with regards to the presence of Popeye deformity.

\begin{tabular}{c|c|c|c|c|c}
\hline \multirow{2}{*}{\begin{tabular}{c} 
Objective evaluation of $\begin{array}{c}\text { objective evaluation of } \\
\text { the examiner } \\
\text { Without Popeye }\end{array}$ \\
\cline { 2 - 5 }
\end{tabular}} & $\begin{array}{c}\text { Obatient } \\
\text { Without } \\
\text { Popeye }\end{array}$ & Popeye & & \multirow{2}{*}{ Total } & P-value \\
\hline \multirow{2}{*}{$\begin{array}{c}\text { Without } \\
\text { Popeye }\end{array}$} & Cases & 41 & 0 & 41 & \\
\cline { 2 - 5 } & $\%$ & $100.0 \%$ & $0.0 \%$ & $100.0 \%$ & \\
\hline \multirow{2}{*}{ Popeye } & Cases & 15 & 7 & 22 & \\
\cline { 2 - 5 } & $\%$ & $68.2 \%$ & $31.8 \%$ & $100.0 \%$ & \\
\hline Total & Cases & 56 & 7 & 63 & \\
\hline & $\%$ & $88.9 \%$ & $11.1 \%$ & $100.0 \%$ & \\
\hline
\end{tabular}

Pearson's chi-square test, with continuity correction, of the association between the objective evaluation of the examiner and the objective evaluation of the patients from the sample.

Table 2 - Occurrence of Popeye deformity according to the examiner, related to the variable age, over or under 60 years.

\begin{tabular}{|c|c|c|c|c|c|}
\hline \multirow{2}{*}{\multicolumn{2}{|c|}{$\begin{array}{l}\text { Objective evaluation } \\
\text { of the examiner } \\
\text { under } 60 \text { years }\end{array}$}} & \multicolumn{2}{|c|}{ Age bracket } & \multirow{3}{*}{$\begin{array}{c}\text { Total } \\
41\end{array}$} & \multirow{3}{*}{$\begin{array}{c}\text { P-value } \\
0.883\end{array}$} \\
\hline & & \multirow{2}{*}{$\begin{array}{c}\begin{array}{c}\text { under } 60 \\
\text { years }\end{array} \\
19\end{array}$} & \multirow{2}{*}{$\begin{array}{c}\begin{array}{c}\text { over } 60 \\
\text { years }\end{array} \\
22\end{array}$} & & \\
\hline $\begin{array}{l}\text { Without } \\
\text { Popeye }\end{array}$ & Cases & & & & \\
\hline & $\%$ & $46.3 \%$ & $53.7 \%$ & $100.0 \%$ & \\
\hline \multirow[t]{2}{*}{ Popeye } & Cases & 9 & 13 & 22 & \\
\hline & $\%$ & $40.9 \%$ & $59.1 \%$ & $100.0 \%$ & \\
\hline \multirow[t]{2}{*}{ Total } & Cases & 28 & 35 & 63 & \\
\hline & $\%$ & $44.4 \%$ & $55.6 \%$ & $100.0 \%$ & \\
\hline
\end{tabular}

Pearson's chi-square test, with continuity correction, of the association between the objective evaluation of the examiner and the age bracket of the patients from the sample.

Table 3 - Analysis of the correlation between physical activity and Popeye deformity, according to the examiner.

\begin{tabular}{c|c|c|c|c|c}
\hline \multirow{2}{*}{$\begin{array}{c}\text { Objective evaluation of } \\
\text { the observer }\end{array}$} & \multicolumn{2}{|c|}{ Physical activity } & \multirow{2}{*}{ Total } & \multirow{2}{*}{ P-value } \\
\cline { 3 - 4 } $\begin{array}{c}\text { Without } \\
\text { Popeye }\end{array}$ & Cases & 32 & 9 & 41 & 0.195 \\
\hline & $\%$ & $78.0 \%$ & $22.0 \%$ & $100.0 \%$ & \\
\hline Popeye & Cases & 13 & 9 & 22 & \\
\hline & $\%$ & $59.1 \%$ & $40.9 \%$ & $100.0 \%$ & \\
\hline Total & Cases & 45 & 18 & 63 & \\
\hline & $\%$ & $71.4 \%$ & $28.6 \%$ & $100.0 \%$ & \\
\hline
\end{tabular}

Pearson's chi-square test, with continuity correction, of the association between the objective evaluation of the observer and the physical activity of the patients from the sample. 


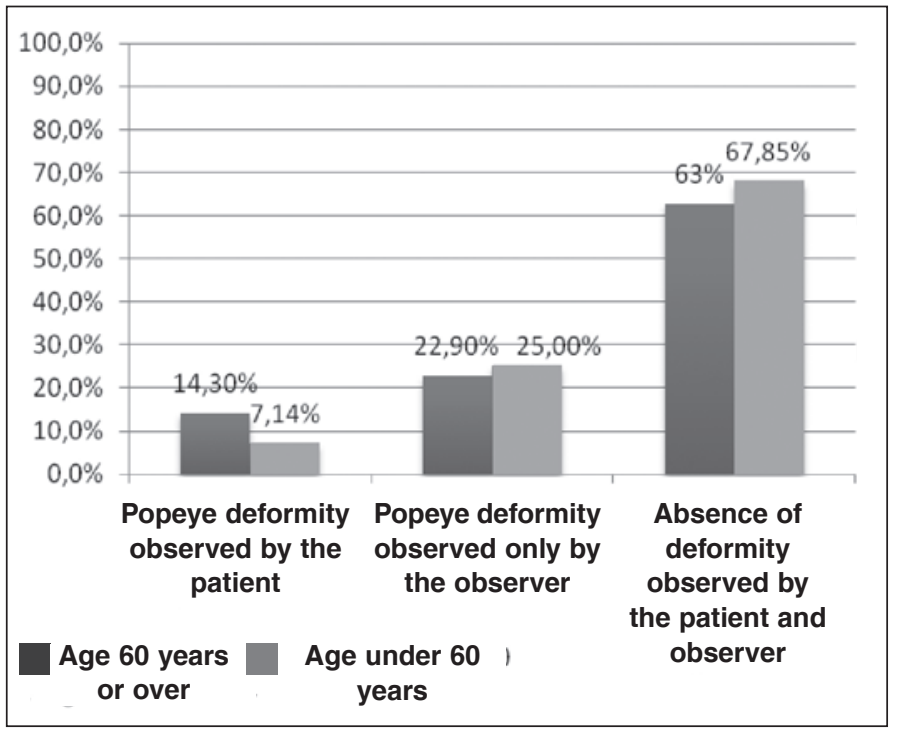

Figure 4 - Occurrence of Popeye deformity according to the evaluation of the patient and of the examiner, relating to the variable age, over or under 60 years $(p=0.883)$.

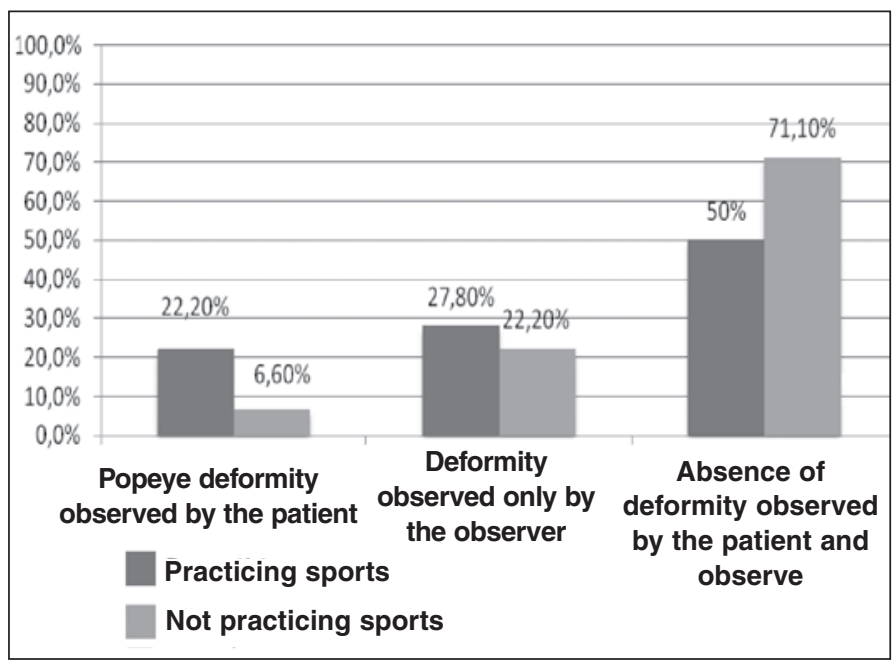

Figure $\mathbf{5}$ - Analysis of the correlation between physical activity and Popeye deformity according to the examiner and the patient. $(p=0.195)$.

Table 4 - Analysis of the correlation between Popeye deformity and lesion of the subscapularis tendon.

\begin{tabular}{c|c|c|c|c|c}
\hline \multirow{2}{*}{$\begin{array}{c}\text { Objective evaluation of } \\
\text { the observer }\end{array}$} & \multicolumn{2}{|c|}{ Subscapularis lesion } & \multirow{2}{*}{ Total } & \multirow{2}{*}{ P-value } \\
\cline { 3 - 5 } & No & Yes & & \\
\hline Without Popeye & Cases & 30 & 11 & 41 & 0.958 \\
\hline & $\%$ & $73.2 \%$ & $26.8 \%$ & $100.0 \%$ & \\
\hline Popeye & Cases & 17 & 5 & 22 & \\
\hline & $\%$ & $77.3 \%$ & $22.7 \%$ & $100.0 \%$ & \\
\hline Total & Cases & 47 & 16 & 63 & \\
\hline & $\%$ & $74.6 \%$ & $25.4 \%$ & $100.0 \%$ & \\
\hline
\end{tabular}

Pearson's chi-square test, with continuity correction, of the association between the objective evaluation of the observer and the subscapularis lesion in the patients from the sample.

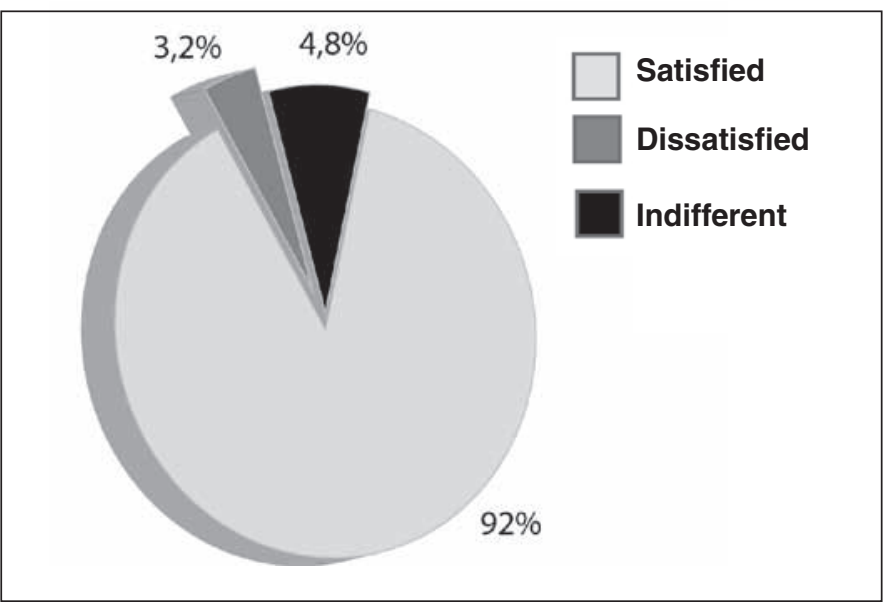

Figure 6 - Degree of satisfaction of the patients according to the esthetic and functional result.

\section{DISCUSSION}

The long head of biceps tendon is a frequent cause of pain in the shoulder. Gilcreest ${ }^{(10)}$ was the first author to describe tenodesis of the long head of the biceps, fixing it in the coracoid process.

Since then, multiple techniques have been described, some with fixation of the tendon in the intertubercular groove $\mathrm{e}^{(11,12)}$ and others with fixation in soft parts, partially or totally by arthroscopic approach ${ }^{(13)}$.

Almeida $e t ~ a l^{(14)}$, in analyzing a group of 77 patients submitted to arthroscopic tenotomy of the long head of biceps tendon, noted that there were no complaints of esthetic deformity in $50(64.9 \%)$ patients, while 27 (35.1\%) expressed some complaint.

In our sample, we observed that the patient perceived residual Popeye deformity after tenodesis in $11.1 \%$ of the cases (seven patients). The complete absence of residual deformity was observed in $65 \%$ (41 patients). The results indicated that there is a relationship between the evaluation of the observer and that of the patient; however, the observer's evaluation to identify the presence of Popeye is more concise than that of the patient $(\mathrm{p}=0.001)$ (Table 1).

Szabó et $a l^{(3)}$ used the criterion of age to indicate tenotomy or tenodesis, preferring tenodesis for more active patients under 60 years of age. The same authors noted that patients aged between 45 and 55 years appear more concerned about the cosmetic aspect of the residual deformity after spontaneous rupture of the biceps long head, which is not the case in patients over 65 years of age, partly due to the atrophy and loss of muscle tone related to age $\mathrm{a}^{(3)}$. 
Besides the concern with the cosmetic aspect, the possible deficit of strength at the level of the elbow and forearm is a recommendation for tenodesis instead of tenotomy, in patients under 55 years of age $e^{(3)}$.

Almeida et $a l^{(14)}$ did not find statistical significance when they performed the cross-evaluation between the patients' ages and the esthetic complaint of residual deformity.

The mean age of the patients in our sample was 55 years, ranging between 32 and 77 years. When we divided the study group into two subgroups, over and under 60 years of age, respectively, we were able to note that the patients' age did not have statistical significance in the cross-evaluation with the occurrence of Popeye deformity $(\mathrm{p}=0.883)$ (Table 2 and Figure 4$)$.

Tenodesis is recommended in physiologically young, active patients under 50 years of age, either in association with or without arthroscopic subacromial decom$\operatorname{pression}^{(15)}$.

Eighteen patients played contact or throwing sports in our study group, corresponding to $28.6 \%$. The statistical analysis showed absence of valid correlation between these sports and the occurrence of Popeye deformity $(p=0.195)$ (Table 3 and Figure 5).

A question that is always raised in relation to the type of technique described concerns its safety when there is deinsertion of the subscapularis tendon, reinserting this tendon in the lesser tubercle in the same surgery.

This condition typically occurs in throwing athletes, requiring the correction of both deformities ${ }^{(15)}$.

In our sample, we observed the association of lesion caused by complete deinsertion of the subscapularis tendon and bicipital lesion, with performance of tenodesis in 14 patients $(22.2 \%)$.

No statistically valid correlation was observed between the subscapularis tendon lesion and its corresponding repair, with the occurrence of residual Popeye deformity $(\mathrm{p}=0.958)$ (Table 4$)$.

Walch et $a l^{(16)}$ observed the presence of Popeye deformity in $50 \%$ of the patients submitted to arthroscopic tenotomy. However, it was observed that the cosmetic deformity of the arm does not usually cause the patient discomfort. Furthermore, no patient characterized its result as fair or poor with a basis on the cosmesis.

The degree of satisfaction of the patients showed 58 satisfied $(92.06 \%)$, two dissatisfied $(3.17 \%)$ and three patients $(4.76 \%)$ who declared themselves indifferent with regards to the residual deformity (Popeye) observed (Figure 6).

\section{CONCLUSION}

"Swiss roll" biceps tenodesis presents high percentages of satisfaction (92.06\%); residual Popeye deformity is perceived by $11.1 \%$ of the patients. Its appearance has no statistically valid correlation with the age bracket over or under 60 years $(p=0.883)$, with sports $(\mathrm{p}=0.195)$ or with the associated lesion of the subscapularis tendon and its repair $(p=0.958)$.

\section{REFERENCES}

1. Yamaguchi K, Bindra R. Disorders of the bíceps tendon. In: lanotti JP, Willians GR Jr, editors. Disorders of the shoulder: diagnosis and management. Philadelphia: Lippincott Williams and Wilkins; 1999. p. 159-90.

2. Ahmad SC, DiSipio C, Lester J, Gardner RT, Levine NW, Bigliani L. Factors affecting dropped biceps deformity after tenotomy of the long head of the biceps tendon. Arthroscopy. 2007;23(5):537-41.

3. Szabó I, Boileau P, Walch G. The proximal biceps as a pain generator and results of tenotomy. Sports Med Arthrosc Rev. 2008;16(3):180-6.

4. Boileau P, Krishnan SG, Coste JS, Walch G. Arthroscopic biceps tenodesis:a new technique using bioabsorbable interference screw fixation. Arthroscopy. 2002;18(9):1002-12.

5. Mazzoca DA, Bicos J, Santangelo S, Romeo AA, Arciero AR. The biomechanical evaluation of four fixation techniques for proximal bíceps tenodesis. Arthroscopy. 2005;21(11):1296-306.

6. Crenshaw AH, Kilgore WE. Surgical treatment of bicipital tenosynovites. J Bone Joint Surg Am.1966;48(8):1496-502.

7. Godinho GG, Souza JMG, Bicalho LA. Reparo das rupturas do manguito rotador do ombro pela videoartroscopia cirúrgica: técnica. Rev Bras Ortop. 1996;31(4):284-8.

8. Cohen J. Statistical power analysis for the behavioral sciences. 2nd. ed. New Jersey: Editora Lawrence Erlbaum Associates; 1988.

9. Triola MF. Introdução à estatística. 7a. ed. Rio de Janeiro: LTC Editora; 1998

10. Gilcreest EL. Two cases of spontaneous rupture of the long head of the bíceps flexor cubiti. Surg Clin North Am. 1926;6:539-54.

11. Lippman RK. Frozen shoulder, periarthritis, bicipital tenosynovitis. Arch Surg. 1943;47:283-96.

12. Hitchcock $\mathrm{HH}$, Bechtol CO. Painful shoulder; observations on the role of the tendon of the long head of the biceps brachii in its causation. J Bone Joint Surg Am. 1948;30(2):263-73.

13. Mazzoca DA, Bicos J, Santangelo S, Romeo AA, Arciero AR. The biomechanical evaluation of four fixation techniques for proximal biceps tenodesis. Arthroscopy. 2005;21(11):1296-306.

14. Almeida A, Roveda G, Scheifler C. Avaliação da deformidade estética após a tenotomia da cabeça longa do bíceps na artroscopia do ombro. Rev Bras Ortop. 2008;43(7):271-8.

15. Busconi BB, DeAngelis N, Guerrero EP. The proximal bíceps tendon:Tricks and pearls. Sports Med Arthrosc Rev. 2008;16(3):187-94.

16. Walch G, Edwards TB, Boulahia A, Nové-Josserand L, Neyton L, Szabo I. Arthroscopic tenotomy of the long head of the biceps in the treatment of rotator cuff tears: clinical and radiographic results of 307 cases. J Shoulder Elbow Surg. 2005;14(3):238-46. 